\title{
Implementation of Active Learning Methodology for Engineering Education
}

\author{
M.Rajendra Prasad ${ }^{1}$, S.Upendra ${ }^{2}$,G.Nagendra ${ }^{3}$ \\ ${ }^{1,2,3}$ Department of ECE, Vidya Jyothi Institute of Technology, Hyderabad, India \\ $\underline{1}$ rajendraresearch@gmail.com \\ 2 upendars@vjit.ac.in \\ 3 nag20209@gmail.com
}

\begin{abstract}
Engineering is the action of working artfully to bring something about, it is very crucial to know the actual practical application of the concepts rather than the traditional bookish knowledge. As we can see a rapid and magnificent growth in the field of technology in the present generation, every student must imbibe complete practical knowledge in order to cope up with the competition in the world. Taking all the drawbacks of classroom learning into account and its negative effects like dearth of practical implementation of concepts, this research completely focuses on the active learning methods which involves the involvement and participation of every student in studying and make expertise the concepts. Keeping all this in mind, this research goes against the present traditional teachinglearning environment and completely supports outcome based education with the concept of integration of practical and classroom learning. This paper focuses on the implementation of Practical and classroom Integrated Learning (PCIL) in the course of Microprocessors and Microcontrollers (MPMC). The implementation is discussed with the case study results.
\end{abstract}

Keywords-Outcome Based Education (OBE), Practical learning, Traditional learning, Practical implementation

\section{Introduction:}

Engineering is a profession which involves constructing, developing and designing many systems based upon the current social requirements. So for development of such robust and reliable systems we need well trained engineers. Today, an engineer is expected to meet the needs of industry and society with excellent expertise in engineering and practical skills. Thus engineering education plays a vital role in educating the students for a better future. An engineering institute today faces many challenges in doing so because the curriculum designed is outdated and no kind of innovative methods of teaching are seen. For a country like India, the transition from traditional teaching to outcome based education is mandatory to make the engineers industry ready .It is very essential to give the students practical learning through the integration of classrooms and labs and industrial interaction. One can understand the principles and laws of any concept when they are aware of the complete practical implementation of it. In order to meet the needs of common people, one has to explore the technology in every possible way and should have thorough knowledge in their field, this is only possible if they are aware of all the functioning of the components in every technology related product. Every student's attitude and the way they see the problem and the way they tackle the problem changes when they are given the correct practical knowledge. For this, its very important for the change in the current educational system and immediate application of the practical methodology is required.

\section{Related work and literature review}

T. Staubitz, H. Klement, J. Renz, R. Teusner and C. Meinel, together worked towards Practical Programming Exercises and Automated Assessment in Massive Open Online Courses. In this paper participants who wish to learn programming, were given an option to work on practical programming exercises and to solve actual programming tasks [1]. Hauke Klement worked on Code Ocean - A versatile platform for practical programming exercises in online environments, where Its concept and implementation are discussed with regard to tools provided to students and teachers, sandboxed and scalable code execution, scalable assessment, and interoperability [2]. M.J.Callaghan, N.Mcshane,A.Gymez Eguyluz developed practical application of the Learning Mechanics-Game Mechanics (LM-GM) framework for Serious Games analysis in engineering education where the ongoing development phase of a game to teach the theoretical and practical principles of the operation of a sound synthesizer is presented to demonstrate how electronic engineering education can be radically reimagined to create immersive, highly engaging learning experiences that are problemcentered and pedagogically sound.[3]. Farhad Shahnia, Moayed Moghbel, Hadi Hosseinian Yengejeh researched on Motivating Power System Protection Course Students by Practical and Computer-Based Activities where the paper presents several methods for motivating students 
taking a power system protection (PSP) course [4]. Son Kuswadi, Ali Ridho Barakbah, Mohammad Nuh developed an integrated project-based learning for Intelligent Control lecture and practice at polytechnics graduate school which enables student learn the knowledge given by lecturer in the classroom, and - together with lecturer - the students design and implement practice in laboratory to get hands on practical ability [5]. This paper proposes PCIL and successfully implemented for various courses in engineering education. a practical teaching/learning methodology when implemented the orientation of students to study will change and our country can witness many future scientists and researchers.

\section{Designing of PCIL Methodology}

The main motto behind introducing the PCIL methodology is to eradicate the drawbacks associated with the traditional way of learning. Classroom teaching can result in the lack of student Focused Learning as it focuses on standards, curriculum and passing tests.The traditional methodology fails in emphasizing on critical thinking,as students need he ability to actively apply the information they gain through experience and reasoning. We find no process oriented learning in the traditional way of teaching.There is no better scope of learning larger concepts or structures under theoretical learning and the major disadvantage it has is the lack of interactivity among the students.Taking all the disadvantages into the account.we started this PCIL methodology as shown in the figure 1 where we give the first preference to the practical learning [6],[7].

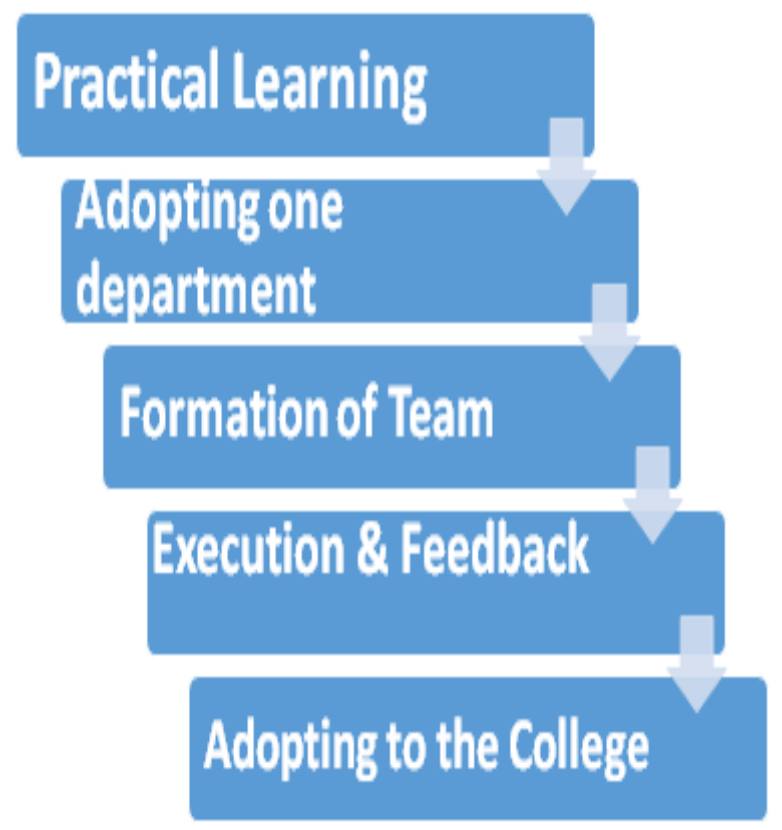

Fig. 1. Flowchart of the PCIL methodology

Practical Learning --- Adopting one department --Formation of Team --- Execution \& Feedback ---
Practical learning indicates learning the theory concepts and implementing them practically. For better understand, the concepts the students can form as groups and with brain storming they can implement the project.

\section{Adopting to the College}

We firstly focus on any one of the departments, and from a team of students in that department. We ask them to decide the most difficult topic in any subject pertaining to their department. We then seek for the help of management to have a laboratory application of the concept and if possible, try to visit the industries which uses that particular concept. After the feedback of all the students and faculty on this kind of teaching methodology, we the extend its wings and implement in every department in the college. For instance, let's take the real time application of 8086 microprocessors and lets also see the comparison between the MASM software and a C software for a same program. In classroom we are taught about the architecture of 8086 processor and the programs related to MASM software are just explained, but the exact functioning of every command or instruction is not known to a student. So here the concept of PCIL comes into the picture. When a student manually writes a program in the MASM software, He/She can easily get awareness regarding the real functioning of the 8086 microprocessor. In theory we find the definitions of physical address, offset address, data segment, code segment, opcode etc. But here by writing a program one can easily understand their definitions by directly looking at the output of any particular program. The course outcomes of MPMC is listed in table 1 and these outcomes are given at the beginning of the semester[7].

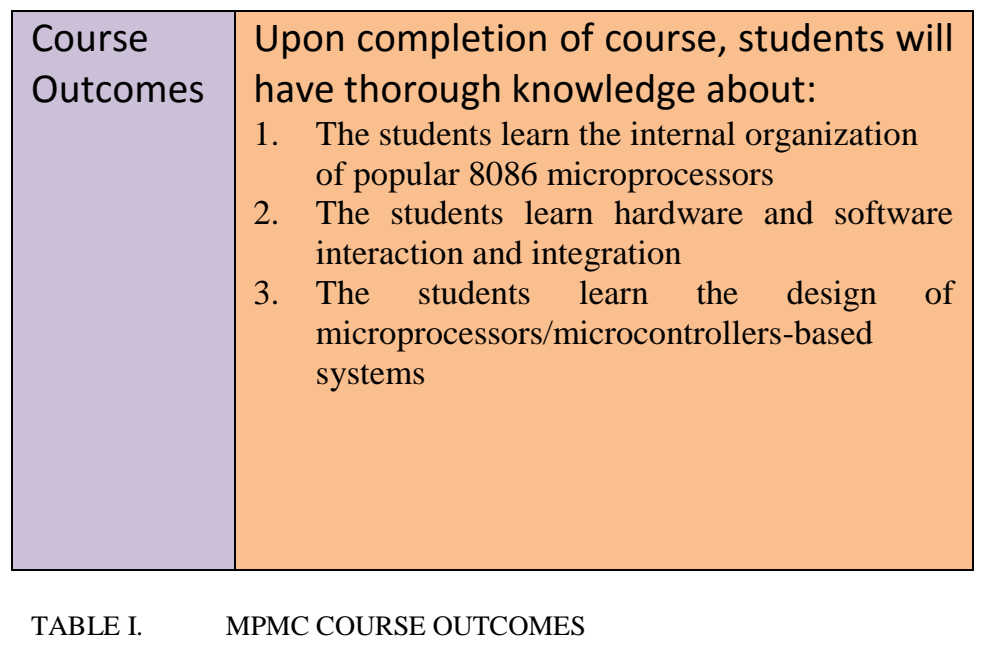

\section{Results and Discussion}

In theory, we learn the definitions of physical address, offset address, code segment, data segment, opcode as following -

A physical address is a binary number in the form of logical high and low states on an address bus that corresponds to a particular cell of primary storage (also 
called main memory), or to a particular register in a memory-mapped i/o(input/output) device.

The offset address in an 8086 is the logical address that the program "thinks about" when it addresses a location in memory. the execution unit (eu or cpu) is responsible for generating the offset address.

Cs (code segment) : code segment (cs) is a 16-bit register containing address of $64 \mathrm{~kb}$ segment with processor instructions. the processor uses cs segment for all accesses to instructions referenced by instruction pointer (ip) register.

Data segment is a 16-bit register containing address of $64 \mathrm{~kb}$ segment with program data. by default, the processor assumes that all data referenced by general registers ( $a x, b x$, $\mathrm{cx}, \mathrm{dx}$ ) and index register ( $\mathrm{si}, \mathrm{di})$ is located in the data segment. ds register can be changed directly using pop and lds instructions.

In computing, an opcode (abbreviated from operation code, also known as instruction syllable or opstrings.) is the portion of a machine language instruction that specifies the operation to be performed. beside the opcode itself, most instructions also specify the data they will process, in the form of operands.

But, when it comes to practical application we can easily understand these terms by just seeing them on the output screen, by doing this every student can gain expertise in the subject and excel in it.

In the below results the program under $\mathrm{C}$ software in linux Operating system and the same program under MASM software are shown and their outputs are observed. In the outputs the physical address, opcode, data segment analysis ,code segment analysis ,offset address are clearly shown and by this every student can clearly understand the concept very well.

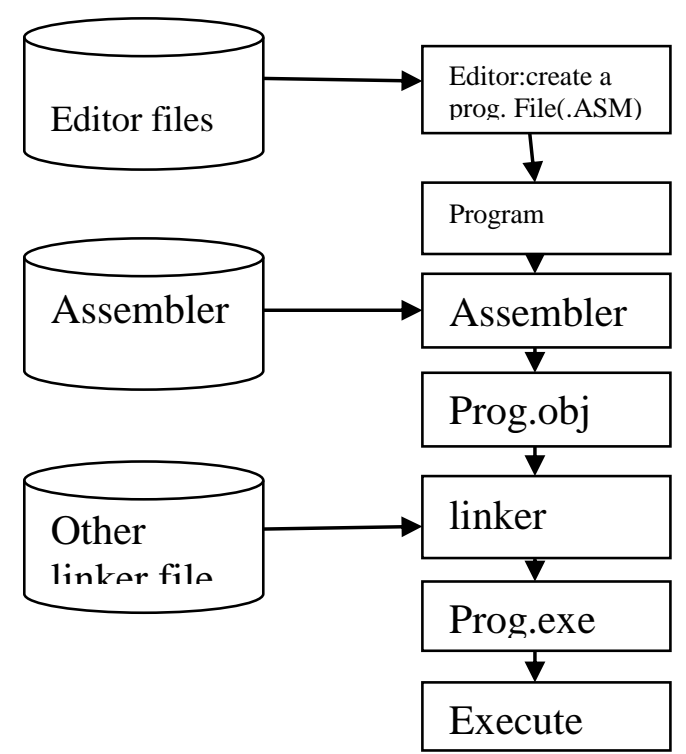

Fig. 2. Flowchart of Assembly level programming.

The flow chart for executing assembly language is shown in the figure 2 . The $\mathrm{C}$ program of sorting the numbers in the ascending order in the Linux operating system and output is as shown in the figure 3 and figure 4.

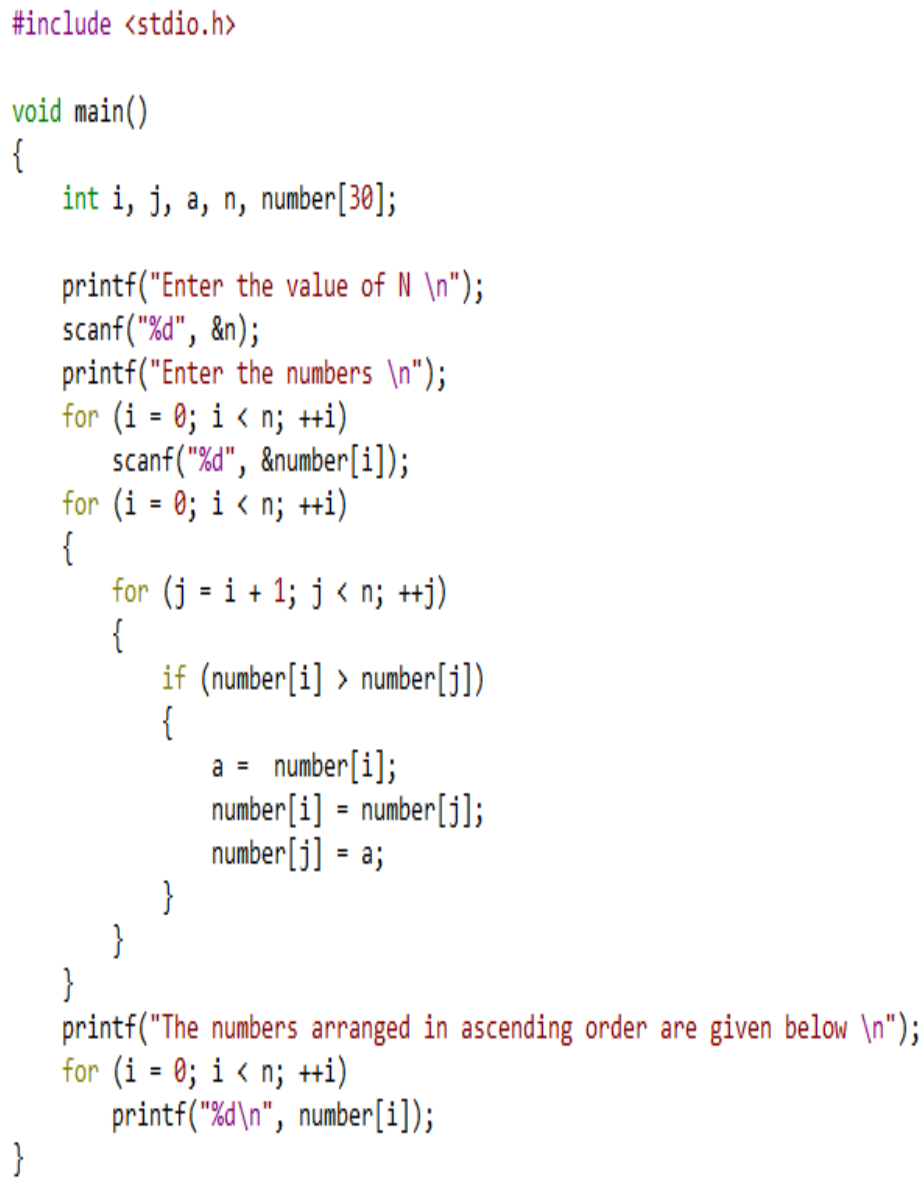

Fig. 3. C Code for the program on LINUX OS

Output: 
Enter the value of $\mathrm{N}$

5

Enter the numbers

11

12

36

22

52

The numbers arranged in ascending order are given below

11

12

22

36

52

Fig. 4. Sorting $\mathrm{C}$ program executed on linux

The high level program is written in $\mathrm{C}$ is developed in 8086 assembly program as shown in the figure 5 with Micro Soft Assembler.

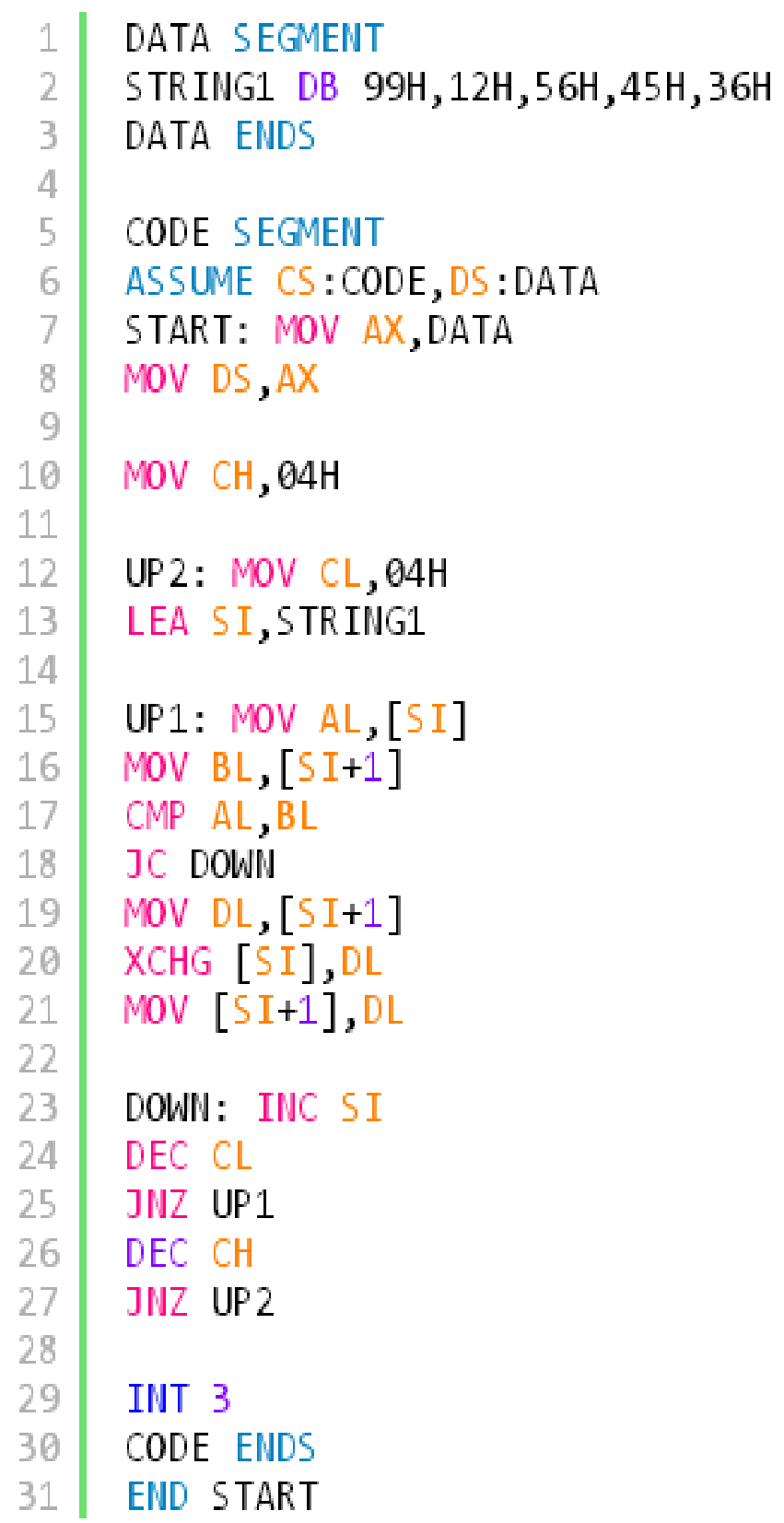

Fig. 5. Assembly Code for the program in MASM software

Using debug system file used in windows operating system we able to display the assembly code as shon in the figure 5.Here the code segment address as $0 \mathrm{~B} 72 \mathrm{~h}$ and physical address of the instruction is specified as $0 \mathrm{~B} 720 \mathrm{~h}$ for first instruction. The opcode for MOV AX, 0B71 opcode is a 3byte length which is B8, 71,0B. Similarly by using PCIL we are able to understand all instructions at system level instructions Using PCIL Similarly by using PCIL we are able to understand all instructions at system level instructions from MOV AX,0B71 to RET as shown in the figure 6. 


\begin{tabular}{|c|c|c|}
\hline 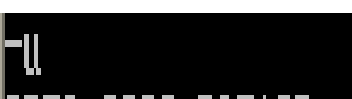 & & \\
\hline 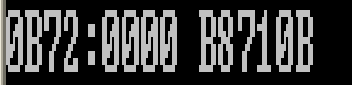 & Ni|ll & AX, , OBPI \\
\hline 972699938078 & 㥏 & DS, Al \\
\hline 9772690955,5944 & IINI & 애,, 44 \\
\hline 97269097 & NiN & 0,64 \\
\hline 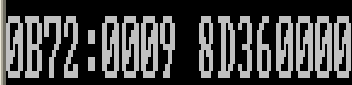 & 泪 & $81,[9090]$ \\
\hline 9726950$) 8944$ & Vill & $A[L,[S]]$ \\
\hline 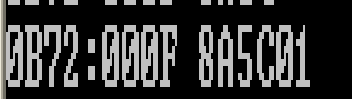 & WiN & $\mathbb{B} 4,[6]+[1] 1]$ \\
\hline 97260912303 & GN & AL, 配 \\
\hline 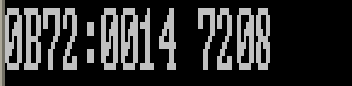 & $\mathbb{W}$ & M \\
\hline 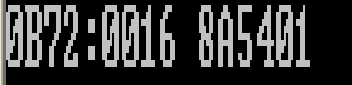 & Villi & 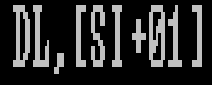 \\
\hline 972768198614 & 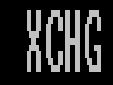 & $\mathbb{W},[8]$ \\
\hline 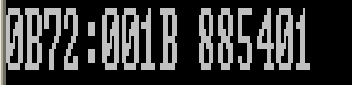 & VIN & $[5]+[1]], 1]$, \\
\hline M7726B81E 46 & IliC & II \\
\hline 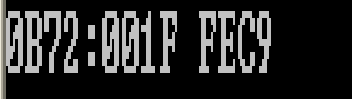 & 洊 & W \\
\hline
\end{tabular}

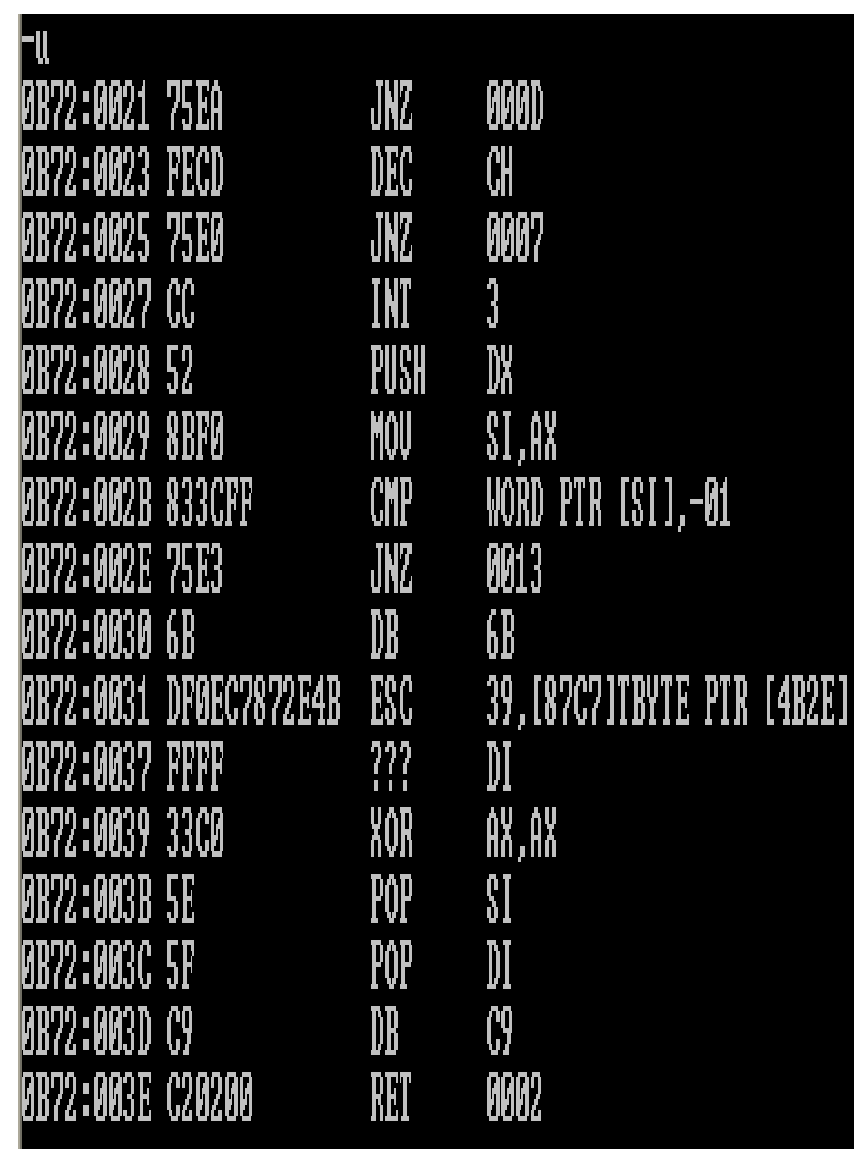

Fig. 6. MASM program with CS address and OPCODES

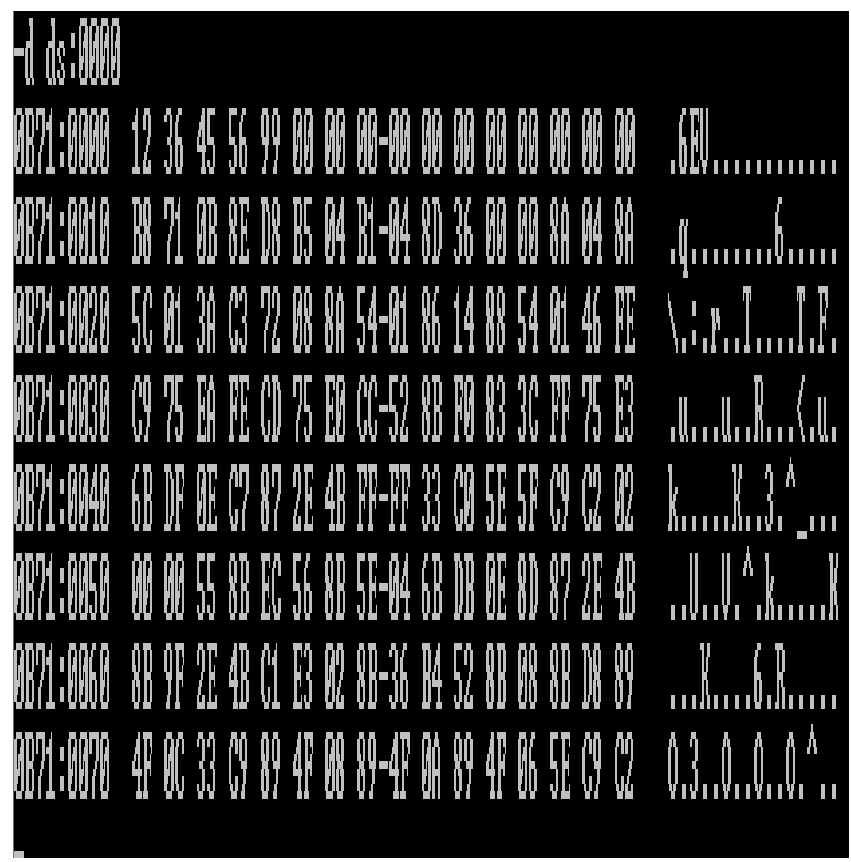

Fig 7 System level analysis of the program

The system level results of assembly program is shown in the figure 7.Here we are analysing the physical address of 20 bit address as $0 \mathrm{~B} 710 \mathrm{H}$ and data segment address as 
OB71.The same $\mathrm{C}$ file is analysed using OBJECT DUM tool in linux operating system as shown in the figure 8 .

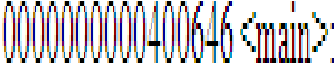

WWG

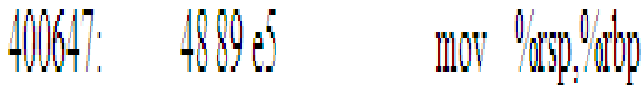

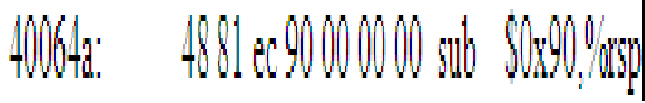

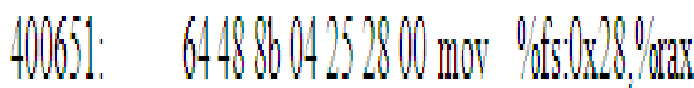

TMGO. MNO

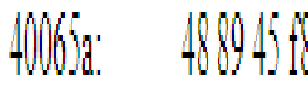

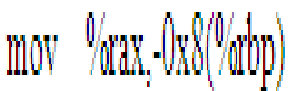

Hobere $310 \mathrm{~d}$

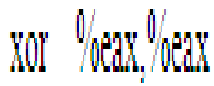

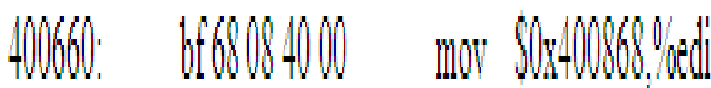

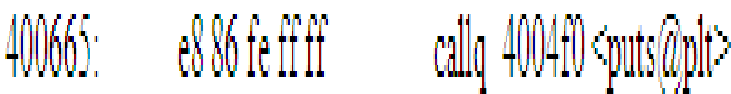

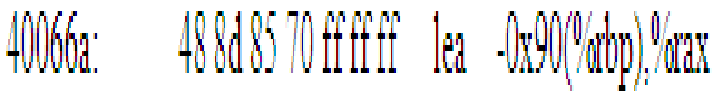

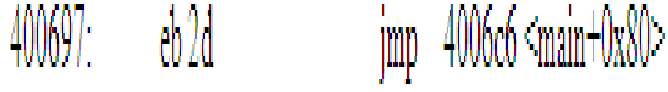

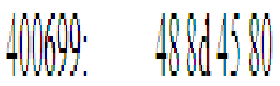

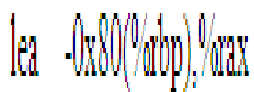

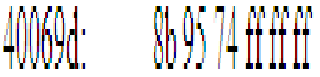

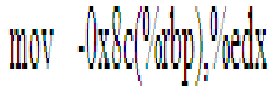

1063: 46602

movelowidy

1066: Hede.

ifl Sily dis

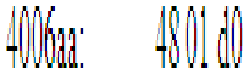

atd "daty

Hord $\quad$ Hog

mov longly

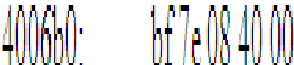

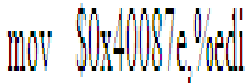

40065

bo00000

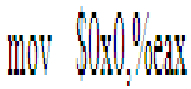

Mble diteffit

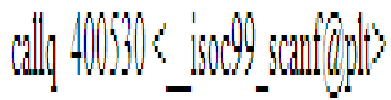

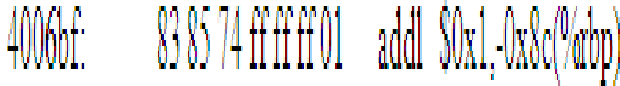

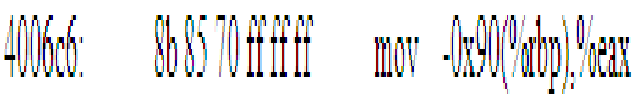

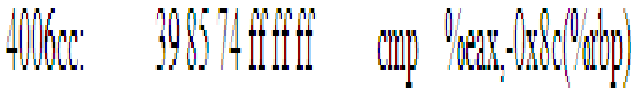

Fig. 8. Object dump code of the program in LINUX C

2.Table which illustrates cpil

\begin{tabular}{|l|l|l|}
\hline Sl.no & \multicolumn{1}{|c|}{ Cpil } & \multicolumn{1}{|c|}{$\begin{array}{c}\text { No of } \\
\text { teachers } \\
\text { involved }\end{array}$} \\
\hline 1. & $\begin{array}{l}\text { The teacher clarifies matheamtical } \\
\text { problems as goal to make the students } \\
\text { understand the basic foundamentals }\end{array}$ & 8 \\
\hline 2. & $\begin{array}{l}\text { The teacher conducts test elict proof of } \\
\text { student learning }\end{array}$ & 15 \\
\hline 3. & $\begin{array}{l}\text { The teachers encourage the students to ask } \\
\text { questions to invoke the students to learn the } \\
\text { new concepts }\end{array}$ & 11 \\
\hline 4. & $\begin{array}{l}\text { The teacher takes feeed back regarding the } \\
\text { concept and improve quality according to } \\
\text { the requirement }\end{array}$ & 15 \\
\hline 5. & $\begin{array}{l}\text { The teacher organise activities to observe } \\
\text { their time management }\end{array}$ & 10 \\
\hline
\end{tabular}




\section{Conclusion}

Therefore, the complete concept of PCIL was developed in Vidya Jyothi Institute Of Technology and successfully got implemented in the electronics and communication department for the course of microprocessor and microcontroller (MPMC).Using PCIL students are able to understand the concepts of register, offset address, physical address and segment address. The students can be assessed with brain storming ,conducting class room test ,the students can reflect their knowledge in laboratory by performing some experiments which they learned in the class room ,the students can also participate in assessment discussion by forming as small groups for concept illustration.

\section{ACKNOWLEDGMENT}

We are immensely grateful to Correspondent, Director, Principal and Head of the Department, ECE of Vidya Jyothi Institute of Technology, Affiliated to JNTUHYDERABAD, for teaching us the importance of Outcome Based Education and the essence of keeping up with emerging technology

\section{REFERENCES:}

[1] T. Staubitz, H. Klement, J. Renz, R. Teusner and C. Meinel, "Towards Practical Programming Exercises and Automated Assessment in Massive Open Online Courses".Published in Teaching,Assessment and Learning for Engineering(TALE),2015 IEEE international conference.

[2] Hauke Klement "CodeOcean - A versatile platform for practical programming excercises in online environments" Published in Global EE conference (EDUCON) 2016,IEEE.

[3] M.J Callaghan,N.Mcshane,A.Gymez Eguyluz. "Practical application of the Learning Mechanics-Game Mechanics (LM-GM) framework for Serious Games analysis in engineering education" published in Remote Engineering and Virtual Intrumentation (REV),2016 13th international conference.

[4] Farhad Shahnia, Moayed Moghbel, Hadi Hosseinian Yengejeh "Motivating Power System Protection Course Students by Practical and Computer-Based Activities" Published in IEEE transactions on education,2016.

[5] Son Kuswadi , Ali Ridho Barakbah ,Mohammad Nuh “An integrated project-based learning for Intelligent Control lecture and practice at polytechnics graduate school" published in Electronics Symposium (IES), 2015 International.

[6] E. L. Boyer, Scholarship Reconsidered: Priorities of the Professoriate. Princeton, NJ, USA: Carnegie Foundation/Jossey-Bass, 1990.

[7] IEEE Transactions on Engineering, "The scholarship of application: Description and review criteria," 2013 [Online]. Available: http://sites.ieee.org/review-criteria-toe/application/

[8] Characteristics of improved formative assessment practice Catarina Andersson \&Torulf Palm Pages 104-122 | Published online: 06 Jan 2017 